\title{
openheart Mid-term outcome of children with latent rheumatic heart disease in eastern Nepal
}

\author{
Nikesh Raj Shrestha, ${ }^{1}$ Dorothea Bruelisauer, ${ }^{2}$ Surendra Uranw, ${ }^{3}$ Rajan Mahato, ${ }^{3}$ \\ Kunjang Sherpa, ${ }^{3}$ Krishna Agrawal, ${ }^{3}$ Martina Rothenbühler, ${ }^{2}$ Prahlad Karki, ${ }^{3}$ \\ Thomas Pilgrim (i) ${ }^{2}$
}

To cite: Shrestha NR, Bruelisauer D, Uranw S, et al. Mid-term outcome of children with latent rheumatic heart disease in eastern Nepal. Open Heart 2021;8:e001605. doi:10.1136/ openhrt-2021-001605

Received 25 January 2021 Revised 19 February 2021 Accepted 18 March 2021

Dheck for updates

(c) Author(s) (or their employer(s)) 2021. Re-use permitted under CC BY-NC. No commercial re-use. See rights and permissions. Published by BMJ.

${ }^{1}$ Department of Cardiology, Neuro Cardio and Multispeciality Hospital, Biratnagar, Nepal ${ }^{2}$ Department of Cardiology, University of Bern, Bern, Switzerland

${ }^{3}$ Department of Internal Medicine and Cardiology, BP Koirala Institute of Health Sciences, Dharan, Nepal

Correspondence to Dr Thomas Pilgrim; thomas. pilgrim@insel.ch

\section{ABSTRACT}

Introduction Systematic echocardiographic screening of children in regions with an endemic pattern of rheumatic heart disease allows for the early detection of valvular lesions suggestive of subclinical rheumatic heart disease. The natural course of latent rheumatic heart disease is, however, incompletely understood at this time. Methods We performed a prospective cohort study of children detected to have echocardiographic evidence of definite or borderline rheumatic heart disease according to the World Heart Federation Criteria.

Results Among 53 children found to have definite (36) or borderline (17) rheumatic heart disease, 44 (83\%) children underwent follow-up at a median of 1.9 years (IQR 1.1-4.5). The median age of the children was 11 years (IQR 9-14) and 34 (64.2\%) were girls. Among children with definite rheumatic heart disease, 21 (58.3\%) were adherent to secondary antibiotic prophylaxis, 7 (19.4\%) were not, information on adherence was missing in $2(5.6 \%)$ children and $6(16.7 \%)$ were lost to followup. Regression of disease was observed in 10 children (27.8\%), whereas 20 children (55.6\%) had stable disease. Among children adherent to secondary prophylaxis, seven (33.3\%) showed regression of disease. Among children with borderline disease, seven (41.2\%) showed regression of disease, three (17.6\%) progression of disease, four $(23.5 \%)$ remained stable and three $(17.6 \%)$ were lost to follow-up. On univariate analysis, we identified no predictors of disease regression, and no predictors for lost to follow-up or non-adherence with secondary antibiotic prophylaxis.

Conclusion Definite rheumatic heart disease showed regression in one in four children. Borderline disease was spontaneously reversible in less than half of the children and progressed to definite rheumatic heart disease in one in five children.

Trial registration number NCT01550068.

\section{INTRODUCTION}

Rheumatic heart disease (RHD) is the leading cause of death from valvular heart disease worldwide and concentrates in lowincome and middle-income countries. ${ }^{1-4}$ Echocardiographic evidence of latent RHD has been documented in 1 in 100 children in

\section{Key questions}

What is already known about this subject?

- Latent rheumatic heart disease has been documented in 1 in 100 children in Nepal and is differentiated into definite and borderline disease according to morphological and functional features. The natural course of latent rheumatic heart disease has not been adequately delineated.

What does this study add?

- We report trajectories of children with latent rheumatic heart disease from a prospective cohort in Nepal with a maximum duration of follow-up of more than 4 years. Definite rheumatic heart disease showed regression in one in four children, while one in five children with borderline disease progressed to definite disease.

How might this impact on clinical practice?

- Our data underscore the importance of timely initiation of secondary antibiotic prophylaxis in children with definite rheumatic heart disease and call for the identification of clinical and echocardiographic characteristics associated with progression of borderline disease.

Nepal and represents a serious public health challenge. $^{5}$

Strategies to mitigate the burden of RHD include population-based echocardiographic screening of children and adolescents in regions with an endemic pattern of disease.$^{6-8}$ Early detection of latent RHD allows for timely implementation of secondary antibiotic prophylaxis. ${ }^{9}$ Reversibility of latent rheumatic valvular lesions is the basic prerequisite for the effectiveness of active surveillance programmes. Cohort studies with longitudinal follow-up are, however, scarce and the natural course of subclinical valvular lesions is incompletely understood.

The aim of the present study was to investigate the trajectory of latent RHD in children and adolescents, and to identify factors 
associated progression and regression of subclinical valvular lesions.

\section{METHODS \\ Setting and design}

We performed a prospective cohort study of children diagnosed with definite or borderline RHD during systematic echocardiographic screening at randomly selected public and private schools in rural and urban regions in Eastern Nepal. Details of the setting of the study have been reported previously. ${ }^{5}{ }^{10}$ In brief, echocardiographic screening was performed by trained physicians using a battery-powered portable ultrasound machine (MySonoU6; Samsung Medison). All children with echocardiographic criteria of RHD detected during screening underwent independent confirmation with a complete echocardiogram at the B.P. Koirala Institute of Health Sciences in Dharan, Nepal. Confirmation examinations were performed using a Hewlett Packard Sonos 1500 cardiac ultrasound by experienced cardiologists according to the criteria of the World Heart Federation (WHF). Cases were defined by complete standard echocardiograms. The interpreters were aware of the clinical variables. Children with morphological features and/or pathological valvular function suggestive of RHD were enrolled into a prospective registry and recommended regular clinical and echocardiographic follow-up. The study complied with the Declaration of Helsinki. All children or their guardians provided written informed consent for participation in this registry.

\section{Definitions and follow-up}

RHD was defined according to the criteria suggested by the WHF for individuals 20 years or younger. ${ }^{11}$ Definite RHD was recorded in the presence of pathological mitral or aortic regurgitation in combination with at least two morphological features of the aortic or the mitral valve, borderline disease of both the mitral and the aortic valve, or evidence of mitral stenosis. Borderline disease was documented in the presence of at least two morphological features of the aortic or the mitral valve, or pathological aortic or mitral regurgitation.

Children fulfilling the criteria for definite RHD were recommended secondary antibiotic prophylaxis with either intramuscular benzathine benzylpenicillin G (BPG) (600000 IU for body weight $<30 \mathrm{~kg}$ and $1200000 \mathrm{IU}$ for patient weight $\geq 30 \mathrm{~kg}$ ) once a month or, alternatively, phenoxymethylpenicillin $250 \mathrm{mg}$ two times per day. Children with borderline RHD were not routinely recommended to start secondary antibiotic prophylaxis. By definition, children were considered adherent to secondary antibiotic prophylaxis if they had received at least two doses of intramuscular BPG or an alternative antibiotic in the 3 months prior to follow-up.

Clinical and echocardiographic follow-up was performed by board-certified cardiologists at B.P. Koirala Institute of Health Sciences. Regression of disease was defined by partial recovery from definite RHD to borderline disease or complete remission of valvular lesions. Progression was defined by worsening of valvular lesions from borderline to definite RHD. Safety endpoints were prospectively recorded and included death, cerebrovascular events, hospitalisations for heart failure, and allergic reactions to penicillin.

\section{Statistical analysis}

Categorical data are represented as frequencies and percentages and differences between groups are evaluated with the $\chi^{2}$ test or Fisher's exact test. Continuous variables are expressed as median values and IQR, and compared between groups using the Wilcoxon rank sum test. The echocardiographic trajectory of children with definite or borderline RHD was explored using spaghetti plots. Univariate logistic regression was performed to identify independent predictors of regression of disease and lost to follow-up or non-adherence to antibiotic prophylaxis. The socioeconomic score was calculated according to the method suggested by Kuppuswamy and adapted by Ghosh and Ghosh. ${ }^{12} 13$ Throughout the present study, a $\mathrm{p}<0.05$ was considered significant. Statistical analyses were performed using Stata V.14.2 (StataCorp).

\section{RESULTS}

Fifty-three children with definite $(\mathrm{n}=36)$ or borderline $(n=17)$ RHD were enrolled into the prospective registry between 13 December 2012 and 15 May 2014. Among children with definite RHD, 35 (97.2\%) had pathological mitral regurgitation in combination with at least two morphological features of RHD of the mitral valve; one child $(2.8 \%)$ had pathological aortic regurgitation in combination with two morphological features of RHD of the aortic valve. Among children with borderline RHD, $10(58.8 \%)$ had at least two morphological features of RHD of the mitral valve without pathological mitral regurgitation or mitral stenosis; 7 children $(41.2 \%)$ had pathological mitral regurgitation.

Forty-four children $(83.0 \%)$ underwent clinical and echocardiographic follow-upata median of 1.9years (IQR 1.1-4.5). The median age of the children was 11 years (IQR 9-14) and 34 were girls $(64.2 \%)$. Baseline characteristics are presented in table 1 and did not differ between children that underwent follow-up and those that were lost to follow-up. One girl with definite RHD died from a non-cardiovascular cause during the course of follow-up. Among children with definite RHD, 21 (58.3\%) were adherent to secondary antibiotic prophylaxis, 7 (19.6\%) were not, information on adherence was missing in 2 children (5.6\%) and $6(16.7 \%)$ were lost to follow-up. Regression of disease was observed in 10 children $(27.8 \%)$, whereas 20 children $(55.6 \%)$ had stable disease (figure 1A, figure 2A). None of the children progressed to manifest RHD requiring intervention. Seven out of 10 children $(70 \%)$ with regression were adherent to secondary antibiotic prophylaxis. Conversely, among children adherent to 
Valvular heart disease

Table 1 Sociodemographic characteristics

$\mathrm{n}=53 \quad \mathrm{n}=15(28.3) \quad \mathrm{n}=38(71.7)$

Individual characteristics

Age, years (median (IQR))

$11(9-14)$

Female sex (n (\%))

34 (64.2)

$9(8-13)$

$12(10-14)$

0.14

Family characteristics

Type of house (n (\%))

10 (66.7)

24 (63.2)

0.81

Kachcha (mud roof)

Tin (tin roof)

Wooden (wooden roof)

Pakka (cement roof)

No of rooms (n (\%))

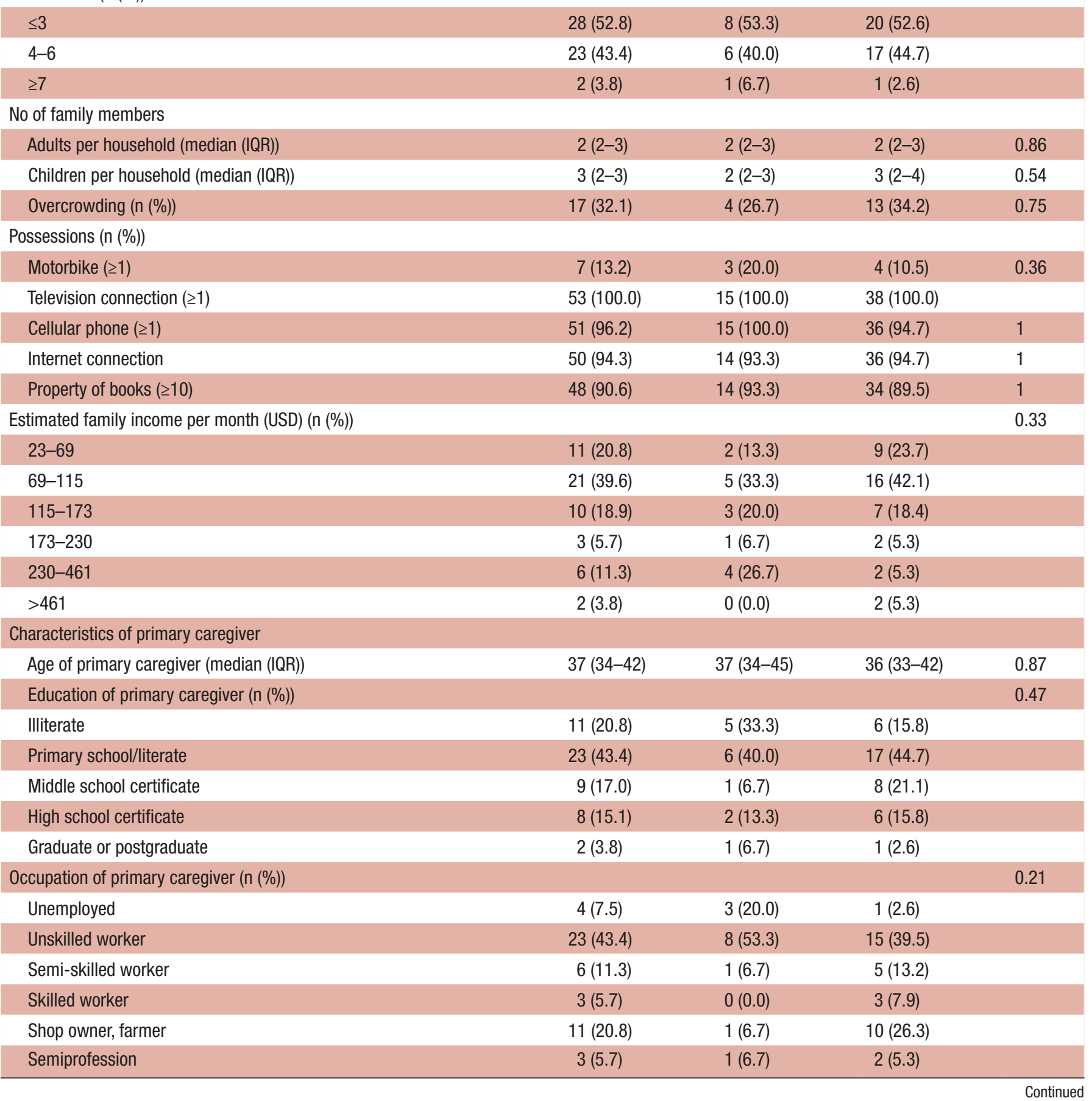

$\begin{array}{clc}10(18.9) & 2(13.3) & 8(21.1) \\ 32(60.4) & 9(60.0) & 23(60.5) \\ 1(1.9) & 0(0.0) & 1(2.6) \\ 10(18.9) & 4(26.7) & 6(15.8)\end{array}$




\section{Table 1 Continued}

\begin{tabular}{lcccc}
\hline & $\mathbf{n = 5 3}$ & $\mathbf{n = 1 5 ( 2 8 . 3 )}$ & $\mathbf{n = 3 8}(\mathbf{7 1 . 7 )}$ & \\
\hline Profession & $3(5.7)$ & $1(6.7)$ & $2(5.3)$ & \\
$\quad$ Socioeconomic score (median (IQR)) & $9(7-12)$ & $8(7-14)$ & $9(7-12)$ & 0.87 \\
Characteristics of the school & & & & \\
$\quad$ Urban school (n (\%)) & $15(28.3)$ & $2(13.3)$ & $13(34.2)$ & 0.13 \\
$\quad$ Governmental school (n (\%)) & $40(75.5)$ & $10(66.7)$ & $30(78.9)$ & 0.35 \\
\hline
\end{tabular}

secondary prophylaxis, seven showed regression of disease (33.3\%). Complete remission of functional and morphological valvular lesions was documented in five children $(13.9 \%)$. The child with pathological aortic regurgitation in combination with two morphological features of RHD of the aortic valve was non-adherent to secondary prophylaxis and remained stable. Among children with borderline disease, seven $(41.2 \%)$ showed regression of disease, three $(17.6 \%)$ progression of disease, four $(23.5 \%)$ remained stable and three $(17.6 \%)$ were lost to follow-up (figure $1 \mathrm{~B}$, figure $2 \mathrm{~A}$ ). Among children with progression of disease, one child had pathological mitral regurgitation at baseline and two children had two morphological features of RHD of the mitral valve without pathological mitral regurgitation or mitral stenosis.

\section{A}

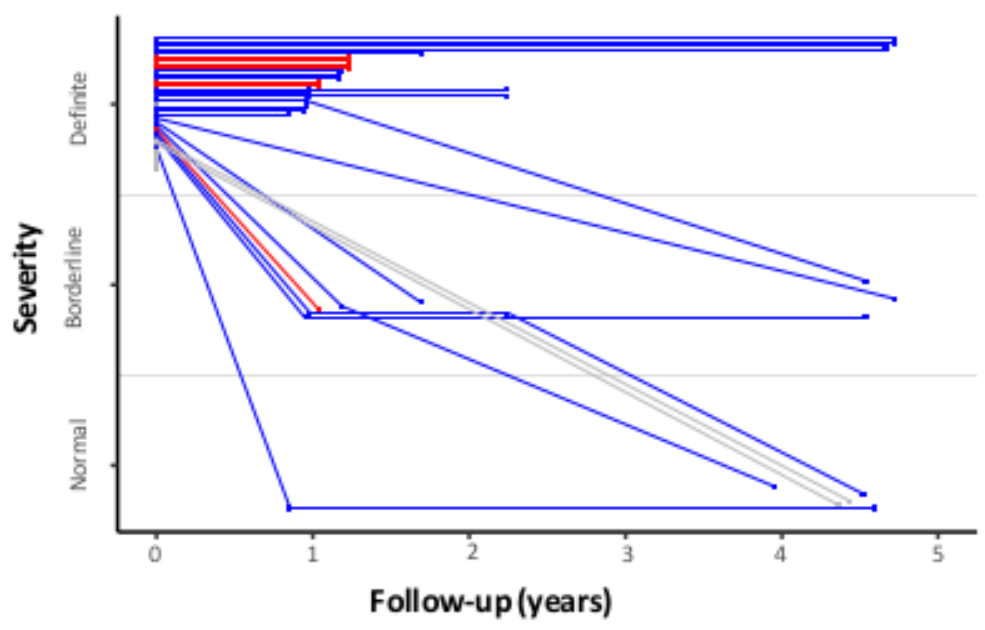

B

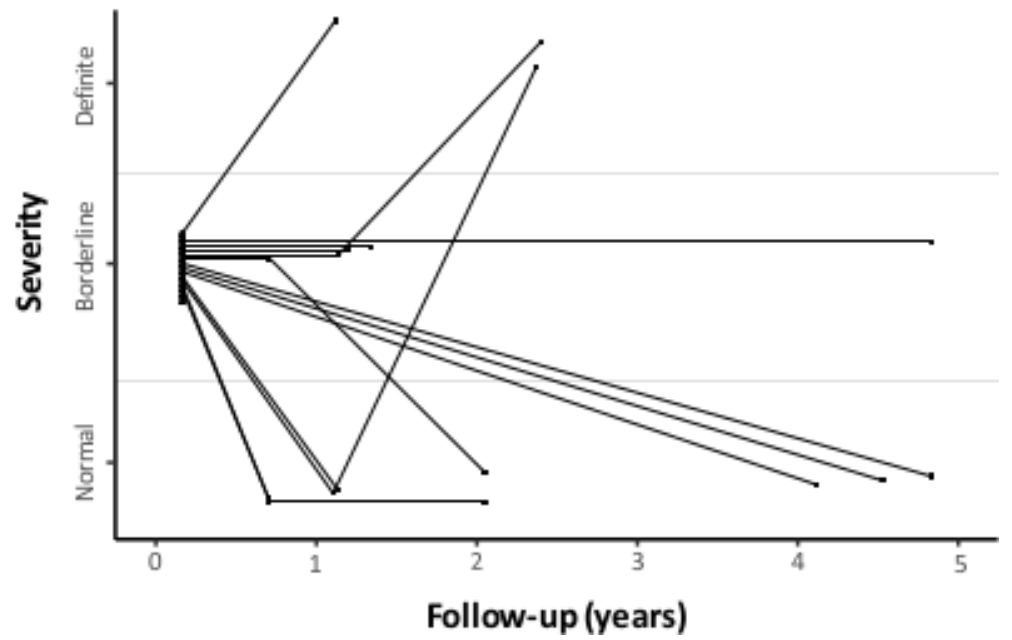

Figure 1 (A) Spaghetti plot displaying longitudinal data of children with definite rheumatic heart disease. Blue lines indicate children that were adherent to secondary antibtiotic prophylaxis. Red lines indicate children that were non-adherent to secondary antibiotic prophylaxis. Light grey lines indicate children with missing information on adherence to secondary antibiotic prophylaxis. (B) Spaghetti plot displaying longitudinal data of children with borderline rheumatic heart disease. 
A

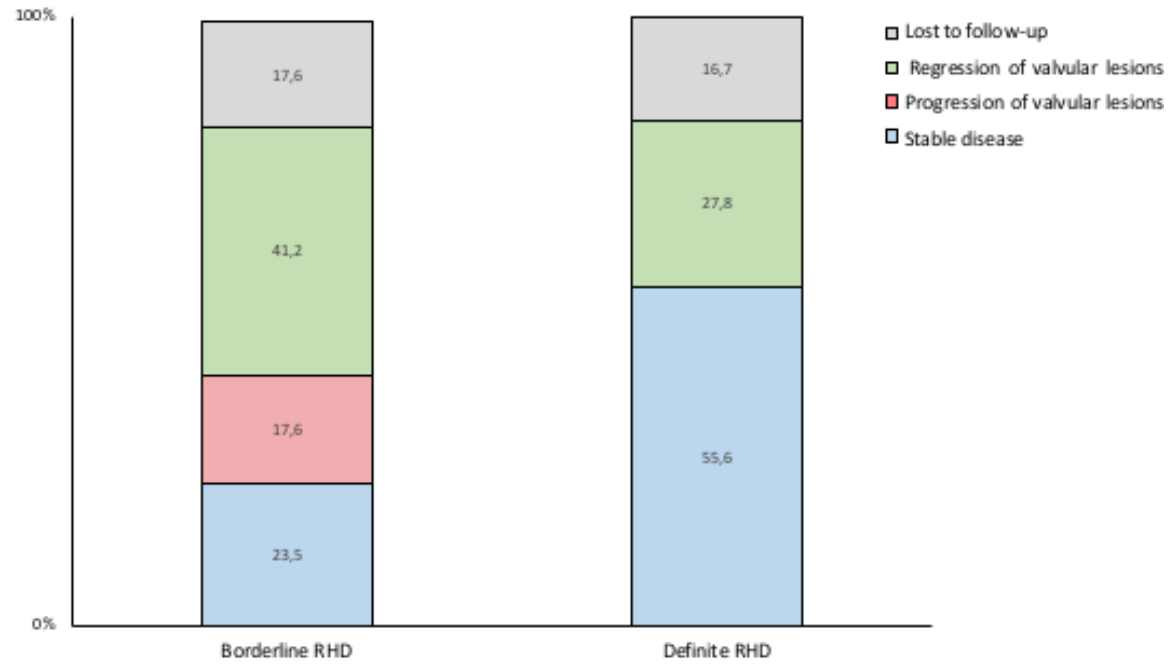

B

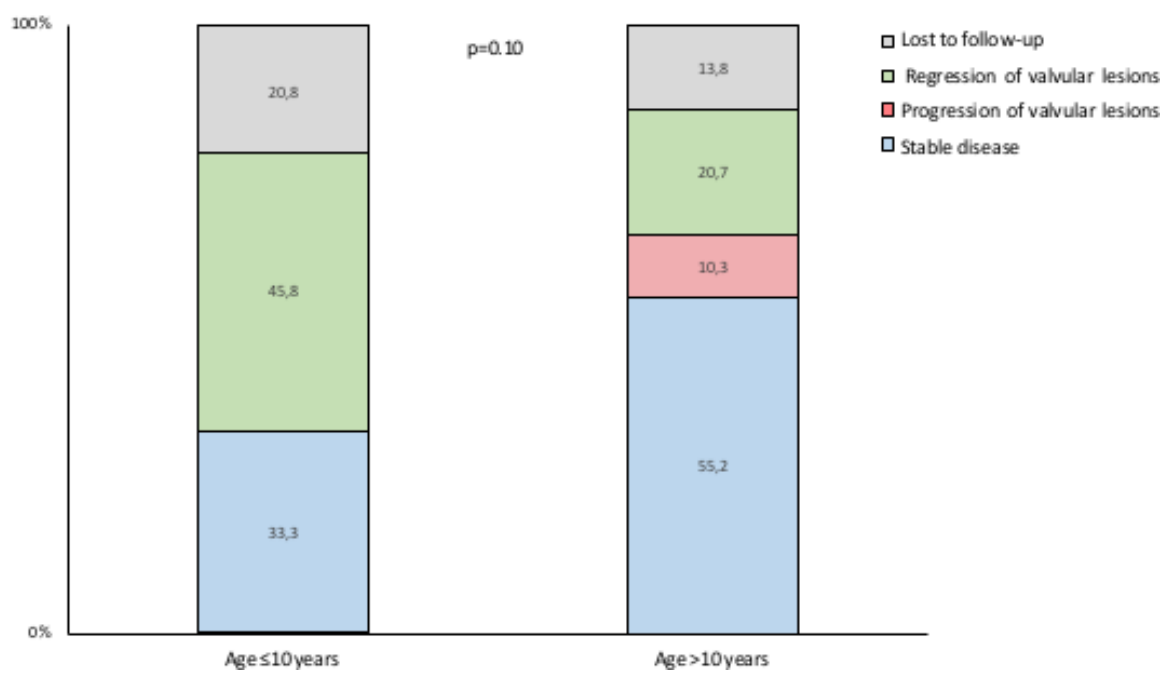

Figure 2 (A) Stacked bar graph illustrating the proportion of children with definite and borderline rheumatic heart disease with regression (green), progression (red) and stable (blue) disease. Children lost to follow-up are shown in grey. (B) Stacked bar graph illustrating the proportion of children $\leq 10$ years of age and $>10$ years of age with regression (green), progression (red) and stable (blue) disease. children lost to follow-up are shown in grey.

Evolution of disease according to WHF category at baseline is summarised in table 2. Disease trajectories according to age are illustrated in figure 2B. In univariate analyses, we identified no predictors of disease regression (table 3), and no predictors for loss to follow-up or non-adherence with secondary antibiotic prophylaxis (table 4).

\section{DISCUSSION}

The salient findings of this prospective cohort study are as follows: (1) Valvular lesions consistent with definite RHD showed regression in one in four children. The majority of children with regression were adherent to secondary antibiotic prophylaxis. and (2)
Borderline disease was spontaneously reversible in less than half of the children and progressed to definite RHD in one in five children.

The findings of our study are consistent with previous reports. Progression of borderline to definite RHD has been reported in 3\%-21\% of children over a follow-up duration of 1.9-2.6 years. ${ }^{14-17}$ Remission of disease over the same time period was described in $32 \%-46 \%$ of children. Definite RHD has been found to show regression in $30 \%-45 \%$ of children. ${ }^{14-17}$ Disease regression has been reported for both children with borderline and definite RHD irrespective antibiotic prophylaxis. ${ }^{17}$ 


\begin{tabular}{|c|c|c|c|c|c|}
\hline & & Regression & Stable disease & Progression & Missing \\
\hline \multicolumn{6}{|c|}{ Definite rheumatic heart disease } \\
\hline A & $\begin{array}{l}\text { Pathological MR and at least two morphological features of } \\
\text { RHD of the MV }\end{array}$ & 10 & 19 & 0 & 6 \\
\hline B & MS mean gradient $\geq 4 \mathrm{~mm} \mathrm{Hg}$ & 0 & 0 & 0 & 0 \\
\hline C & $\begin{array}{l}\text { Pathological AR and at least two morphological features of RHD } \\
\text { of the AV }\end{array}$ & 0 & 1 & 0 & 0 \\
\hline D & Borderline disease of both the AV and MV & 0 & 0 & 0 & 0 \\
\hline \multicolumn{6}{|c|}{ Borderline rheumatic heart disease } \\
\hline A & $\begin{array}{l}\text { At least two morphological features of RHD of the MV without } \\
\text { pathological MR or MS }\end{array}$ & 2 & 4 & 2 & 2 \\
\hline B & Pathological MR & 2 & 3 & 1 & 1 \\
\hline C & Pathological AR & 0 & 0 & 0 & 0 \\
\hline
\end{tabular}

$\mathrm{AR}$, aortic regurgitation; AV, aortic valve; MR, mitral regurgitation; MS, mitral stenosis; MV, mitral valve; RHD, rheumatic heart disease; WHF, World Heart Federation.

We identified no demographic markers predicting individual risk of disease progression or regression in the present study. Risk stratification of children with latent RHD is important to guide treatment strategy. Drivers of disease progression are however incompletely understood at this time. Nunes et al suggested echocardiographic criteria for the prediction of progression of latent RHD. ${ }^{18}$ The validated score considers echocardiographic variables of the mitral valve such as anterior leaflet thickening (three points), excessive leaflet tip motion (three points) or an excessive regurgitant jet (six points), and variables of the aortic valve such as irregular or focal thickening (four points) and any regurgitation (five points). Children with a risk score $\geq 10$ were found to have a risk of progression of $\geq 25 \%$. $^{18}$

Medical management of children with latent RHD is matter of debate. Observational data from longitudinal cohort studies provided no robust evidence for the effectiveness of antibiotic prophylaxis in children with latent RHD at the time of initiation of our study. We, therefore, opted for a pragmatic approach prescribing antibiotic prophylaxis to all children with definite RHD while recommending regular echocardiographic follow-up in children with borderline disease. The GwokO Adunu pa Lutino trial is an ongoing randomised controlled trial designed to determine the impact of secondary antibiotic

\begin{tabular}{|c|c|c|}
\hline & Risk ratio $(95 \% \mathrm{Cl})$ & $P$ value \\
\hline Age & 0.91 (0.73 to 1.15$)$ & 0.44 \\
\hline Female gender & 1.22 (0.38 to 3.96$)$ & 0.74 \\
\hline Socioeconomic score & 1.01 (0.88 to 1.15$)$ & 0.93 \\
\hline Urban school & 2.15 (0.63 to 7.37$)$ & 0.22 \\
\hline Governmental school & $0.77(0.21$ to 2.82$)$ & 0.69 \\
\hline
\end{tabular}

prophylaxis in children with latent RHD on echocardiographic progression at 2 years, and is anticipated to inform the standard of care in children with borderline or mild definite RHD. ${ }^{19}$

Table 4 Univariate predictors of loss to follow-up or nonadherence to secondary antibiotic prophylaxis

\begin{tabular}{|c|c|c|}
\hline & Risk ratio $(95 \% \mathrm{Cl})$ & $P$ value \\
\hline \multicolumn{3}{|l|}{ Individual characteristics } \\
\hline Age & 0.81 (0.63 to 1.04) & 0.097 \\
\hline Female gender & $0.75(0.21$ to 2.60$)$ & 0.65 \\
\hline \multicolumn{3}{|l|}{ Family characteristics } \\
\hline \multicolumn{3}{|l|}{$\begin{array}{l}\text { Characteristics of primary } \\
\text { caregiver }\end{array}$} \\
\hline \multicolumn{3}{|c|}{$\begin{array}{l}\text { Education of primary caregiver } \\
(\mathrm{n}(\%))\end{array}$} \\
\hline Illiterate & 2.35 (0.60 to 9.26$)$ & 0.22 \\
\hline Primary school/literate & 1.02 (0.31 to 3.33$)$ & 0.97 \\
\hline Middle school certificate & 0.24 (0.03 to 2.12) & 0.20 \\
\hline High school certificate & 0.74 (0.13 to 4.12$)$ & 0.73 \\
\hline Graduate or postgraduate & 2.40 (0.14 to 40.94 & 0.55 \\
\hline \multicolumn{3}{|c|}{$\begin{array}{l}\text { Occupation of primary caregiver (n } \\
\%) \text { ) }\end{array}$} \\
\hline Unemployed & 8.31 (0.79 to 87.15$)$ & 0.078 \\
\hline Unskilled worker & 1.47 (0.45 to 4.77$)$ & 0.52 \\
\hline Semiskilled worker & 0.43 (0.05 to 3.98$)$ & 0.45 \\
\hline Shop owner, farmer & 0.44 (0.08 to 2.34$)$ & 0.34 \\
\hline Semiprofession & 1.17 (0.10 to 13.87$)$ & 0.90 \\
\hline Profession & 1.17 (0.10 to 13.87$)$ & 0.90 \\
\hline Socioeconomic status & 1.04 (0.91 to 1.20$)$ & 0.54 \\
\hline \multicolumn{3}{|l|}{ Characteristics of the school } \\
\hline Urban school & 0.26 (0.05 to 1.34$)$ & 0.11 \\
\hline Governmental school & 0.39 (0.11 to 1.43$)$ & 0.16 \\
\hline
\end{tabular}


Investment in comprehensive programmes is needed to mitigate the burden of RHD in regions with an endemic pattern of disease. Strategies to target RHD include epidemiologic surveillance, public awareness and health education programmes, as well as primary and secondary prevention. $^{20}$

The present study needs to be interpreted in light of several limitations. First, the prospective cohort study included a modest number of children with variable duration of follow-up and an attrition rate of $17 \%$. Second, adherence to antibiotic prophylaxis was arbitrarily defined based on the 3 months prior to follow-up and did not rely on comprehensive healthcare records or patient diaries. Hence, we cannot draw conclusions on the relationship between disease regression and adherence to secondary antibiotic prophylaxis. Third, there are different criteria to define RHD. We used the widely accepted WHF criteria for the purpose of the present analysis. The outcome may have been slightly different if other criteria would have applied. And finally, in the absence of validated criteria, we did not quantify echocardiographic progression of definite RHD.

In conclusion, in a prospective cohort of children with latent RHD in Nepal, valvular lesions consistent with definite RHD showed regression in one in four children, while one in five children with borderline disease progressed to definite RHD.

\section{Twitter Krishna Agrawal @agrawalkris and Thomas Pilgrim @ThomPilgrim}

Contributors NS and TP conceived the study. NS and TP had responsibility for the design of the study. NS, DB, SU, RM, KS, KA and PK were responsible for acquisition of the data. TP and MR did the analysis and interpreted the results in collaboration with NS and DB. DB and TP wrote the first draft of the report. All authors critically revised the report for important intellectual content and approved the final version.

Funding The study was supported by a research grant from the UBS Optimus Foundation, Switzerland.

Disclaimer The funding source was not involved in the design and conduct of the study, collection, management, analysis and interpretation of the data; nor in preparation, review, or approval of the manuscript and decision to submit the manuscript for publication.

Competing interests TP has received research grants to the institution from Biotronik, Boston Scientific and Edwards Lifesciences, speaker fees from Biotronik and Boston Scientific, serves as a consultant for HighLife SAS, and is a proctor for Medtronic and Boston Scientific.

Patient consent for publication Not required.

Ethics approval The study was approved by the institutional review board of B.P. Koirala Institute of Health Sciences (reference number 163/068/069) and the Nepal Health Research Council (reference number 273).

Provenance and peer review Not commissioned; externally peer reviewed.

Data availability statement Data are available in a public, open access repository. Data will be available at www.rhedproject.org.

Open access This is an open access article distributed in accordance with the Creative Commons Attribution Non Commercial (CC BY-NC 4.0) license, which permits others to distribute, remix, adapt, build upon this work non-commercially, and license their derivative works on different terms, provided the original work is properly cited, appropriate credit is given, any changes made indicated, and the use is non-commercial. See: http://creativecommons.org/licenses/by-nc/4.0/.

ORCID iD

Thomas Pilgrim http://orcid.org/0000-0001-8721-4068

\section{REFERENCES}

1 Watkins DA, Johnson CO, Colquhoun SM, et al. Global, regional, and national burden of rheumatic heart disease, 1990-2015. N Engl J Med 2017;377:713-22.

2 Yadgir S, Johnson CO, Aboyans V, et al. Global, regional, and national burden of calcific aortic valve and degenerative mitral valve diseases, 1990-2017. Circulation 2020;141:1670-80.

3 Marijon E, Mirabel M, Celermajer DS, et al. Rheumatic heart disease. The Lancet 2012;379:953-64.

4 Rothenbühler M, O'Sullivan CJ, Stortecky S, et al. Active surveillance for rheumatic heart disease in endemic regions: a systematic review and meta-analysis of prevalence among children and adolescents. Lancet Glob Health 2014;2:e717-26.

5 Shrestha NR, Karki P, Mahto R, et al. Prevalence of subclinical rheumatic heart disease in eastern Nepal: a school-based crosssectional study. JAMA Cardiol 2016;1:89-96.

6 Marijon E, Ou P, Celermajer DS, et al. Prevalence of rheumatic heart disease detected by echocardiographic screening. N Engl J Med 2007;357:470-6.

7 Beaton A, Okello E, Lwabi P, et al. Echocardiography screening for rheumatic heart disease in Ugandan schoolchildren. Circulation 2012;125:3127-32.

8 Saxena A, Ramakrishnan S, Roy A, et al. Prevalence and outcome of subclinical rheumatic heart disease in India: the RHEUMATIC (Rheumatic Heart Echo Utilisation and Monitoring Actuarial Trends in Indian Children) study. Heart 2011;97:2018-22.

9 Karki P, Uranw S, Bastola S, et al. Effectiveness of systematic echocardiographic screening for rheumatic heart disease in Nepalese schoolchildren: a cluster randomized clinical trial. JAMA Cardiol 2021. doi:10.1001/jamacardio.2020.7050. [Epub ahead of print: 20 Jan 2021] (Published Online First: 20 January 2021).

10 Pilgrim T, Kalesan B, Karki P, et al. Protocol for a populationbased study of rheumatic heart disease prevalence and cardiovascular outcomes among schoolchildren in Nepal. BMJ Open 2012;2:e001320.

11 Reményi B, Wilson N, Steer A, et al. World Heart Federation criteria for echocardiographic diagnosis of rheumatic heart disease--an evidence-based quideline. Nat Rev Cardiol 2012;9:297-309.

12 Kuppuswamy B. Manual of socioeconomic status (Urban. Delhi: Manasayan, 1981.

13 Ghosh A, Ghosh T. Modification of Kuppuswamy's Socioeconomic Status Scale in context to Nepal. Indian Pediatr 2009;46:1105.

14 Sanyahumbi A, Beaton A, Guffey D, et al. Two-Year evolution of latent rheumatic heart disease in Malawi. Congenit Heart Dis 2019;14:614-8

15 Bertaina G, Rouchon B, Huon B, et al. Outcomes of borderline rheumatic heart disease: a prospective cohort study. Int J Cardiol 2017;228:661-5.

16 Zühlke L, Engel ME, Lemmer CE, et al. The natural history of latent rheumatic heart disease in a 5 year follow-up study: a prospective observational study. BMC Cardiovasc Disord 2016;16:46.

17 Beaton A, Aliku T, Dewyer A, et al. Latent rheumatic heart disease: identifying the children at highest risk of unfavorable outcome. Circulation 2017;136:2233-44.

18 Nunes MCP, Sable C, Nascimento BR, et al. Simplified echocardiography screening criteria for diagnosing and predicting progression of latent rheumatic heart disease. Circ Cardiovasc Imaging 2019;12:e007928.

19 Beaton A, Okello E, Engelman D, et al. Determining the impact of benzathine penicillin $\mathrm{G}$ prophylaxis in children with latent rheumatic heart disease (goal trial): study protocol for a randomized controlled trial. Am Heart J 2019;215:95-105.

20 Marijon E, Celermajer DS, Jouven X. Rheumatic Heart Disease - An Iceberg in Tropical Waters. N Engl J Med 2017;377:780-1. 